\title{
FEITOS ESTILIZADOS DO PATRÓN DE INVESTIMENTO NA ECONOMÍA ESPAÑOLA
}

(1981-2013)

Luis Cárdenas del Rey luiscard@ucm.es

Universidade Isabel I e Universidade Complutense de Madrid

\section{Resumo}

O obxecto principal deste traballo é presentar un conxunto de feitos estilizados sobre o patrón de investimento que amosou a economía española nas derradeiras décadas. A realización deste tipo de análise é relevante como punto de partida para posteriores estudos sobre o investimento en España, especialmente pola importancia central que ten o investimento no crecemento económico. Utilízanse os datos da base BBVA-IVIE pero cun enfoque metodolóxico distinto, máis achegado ás categorías do BEA estadounidense. Grazas a isto, neste traballo apórtase nova evidencia sobre os trazos característicos do patrón de capitalización, dos que os máis interesantes son: i) Existiu unha "aceleración" no crecemento entre os dous ciclos expansivos; ii) A nivel de composición técnica, o investimento en equipamentos é o que amosou un maior dinamismo; iii) a nivel de axentes investidores, o investimento corporativo tivo unha gran constancia no seu crecemento, véndose complementado polo "relevo" dos outros axentes, é dicir, o investimento das AA.PP: creceu máis no primeiro ciclo expansivo (1981-1993) e o investimento dos fogares no segundo (1994-2007), e iv) a nivel sectorial o investimento concentrouse en sectores con maior dinamismo en creación de emprego, sendo paradigmático o caso do sector da construción.

Palabras chave: Investimento, feitos estilizados, economía española

Title: Some stylized facts on investment patterns of the Spanish economy (1981-2013)

\begin{abstract}
The main aim of this report is to introduce a set of stylized facts about the investment pattern displayed by the Spanish economy in the past decades. This type of analysis is relevant as a starting point for further studies on investment in Spain, especially given the importance of investment in economic growth. Information from the BBVA-IVIE database has been used with a different methodological approach, closer to the categories of the American BEA. As a result, new evidence is exposed along with the characteristics of the capitalization pattern, of which the most interesting ones are the following: (i) There was an "acceleration" in growth between both expansive cycles. (ii) As far as technical composition is concerned, investment in equipment is the one that has been more dynamic. (iii) From the agent investment point of view, business capitalization has been hugely consistent with growth, being complemented by the "relay" of the other two agents, i.e., the government investment in the first expansionary cycle (1981-1993) and household investment in the second (1994-2007). (iv) At a sectoral level, investment has been concentrated in industries with greater dynamism in terms of job creation and, in this sense, the building industry is paradigmatic.
\end{abstract}

Keywords: Investment, stylized facts, Spanish economy

Jel code: E20, E22, E32

\section{Introdución}

Neste traballo abórdase a obtención e sistematización dos principais feitos observados no comportamento do patrón de capitalización, pola especial relevancia desta macromagnitude, da economía española durante o período 1981-2013, tomando como referencia e punto de partida o traballo de Más, Pérez e Uriel (2015) e a base de datos 
descrita neste estudo (en adiante BBVA-IVIE'1).

A principal diferenza metodolóxica, con respecto á literatura especializada, consiste en trasladar as categorías utilizadas na BBVA-IVIE ás categorías seguidas polo Bureau of Economic Analysis (2014). Esta transformación consiste en distinguir a composición técnica entre: i) investimento en instalacións (structures); e ii) investimento en equipamentos (equipment and software). Ademais, distinguiremos a composición institucional, é dicir, en función do axente que realiza o investimento: i) o investimento dos fogares corresponde ao investimento residencial en vivendas (residential structures), ii) o investimento das Administracións Públicas (AA.PP.) en infraestruturas (government structures and equipments) e iii) o investimento corporativo privado (private structures and equipments).

Esta clasificación presenta varias vantaxes á hora da análise dos feitos estilizados: por unha banda, permite vencellar os trazos observados ás análises do ciclo económico porque son conceptos máis achegados aos que xeralmente se utilizan nestes estudos (as categorías da Contabilidade Nacional Trimestral); e por outra banda, a clasificación por axentes investidores ofrece unha base aos estudos que opten por microfundamentar as flutuacións do investimento agregado.

O período seleccionado da mostra responde ás datas cíclicas ${ }^{2}$ da evolución económica da economía española, pero a diferenza desta clasificación o punto máis baixo da acumulación do stock de capital (tanto en FBCF como na valoración do stock de capital) prodúcese no ano 1981, polo que tomaremos ese dato como ano base, existindo, polo tanto, dous períodos cíclicos de expansión cunha duración semellante: 1981-1993 e 19942007. A efectos comparativos engádese tamén o período posterior ao ano 2008, pero dada a brevidade do período de auxe a partir dese ano, pola existencia da "dobre recesión", e a substancial diferenza na duración da actual fase expansiva con respecto ás anteriores, prestaráselle menor atención.

A principal contribución é, como consecuencia do enfoque metodolóxico, aportar nova evidencia e con iso contribuír á identificación dos trazos do patrón de acumulación, sendo un paso necesario para posteriores estudos sobre as súas causas e consecuencias, e de interese para os investigadores interesados na materia.

A estrutura do documento é a seguinte, primeiro elabórase a base de datos para constatar os feitos a un nivel agregado, e, a continuación, séguenlle tres apartados onde se analiza a evidencia dende unha perspectiva agregada, dende unha perspectiva institucional (por tipos de axentes) e dende unha perspectiva sectorial. Remátase coas conclusións.

\section{Elaboración e reclasificación da base de datos}

Como se sinalou, o criterio metodolóxico, para distinguir a composición técnica do investimento, agrupouse en dúas categorías: i) o investimento en instalacións abrangue tanto o investimento en vivendas non domésticas e, principalmente, o concepto doutras construcións (infraestruturas e outros); ii) O investimento en equipamentos inclúe todos

\footnotetext{
${ }^{1}$ A base pódese consultar na web: www.fbbva.es/TLFU/microsites/ stock09/fbbva_stock08 index.html

2 O Comité de Datado do Ciclo Económico Español (http:/ / asesec.org/ comites/ comite-de-fechado) estableceu as fases de expansión e recesión, de forma semellante ao método desenvolvido polo National Bureau of Economic Research (NBER) para Estados Unidos.
} 
os investimentos en maquinaria e bens de equipo, equipos de transporte, activos cultivados, e activos inmateriais (software e outros activos inmateriais).

Á hora de distinguir por axentes optouse por:

- Investimento dos fogares: definido como o investimento residencial doméstico neste caso, aproximado mediante 0 investimento en vivendas no sector inmobiliario (clasificado como "7. Actividades inmobiliarias").

- Investimento das AA.PP., que cobre o realizado por todas as institucións públicas, pero sen incluír o investimento das empresas públicas, o que supón a suma dos epígrafes seguintes: i) 9.1. Administración pública; ii) 9.2. Educación pública; iii) 9.4. Sanidade pública, e iv) 9.5. Servizos sociais públicos. Tanto en instalacións como equipamentos (sendo o primeiro máis do $80 \%$ do conxunto).

- Investimento realizado polas empresas, que se define en consecuencia como o investimento total descontado o investimento dos outros dous axentes. En consecuencia, o investimento inmobiliario corporativo non conta co investimento en vivendas (pero si o resto de tipos) e o investimento da administración é só o realizado polo sector privado.

Como se pode observar, os datos dispoñibles BBVA-IVIE non permiten unha asignación absolutamente precisa ás categorías desexadas, pero si aproximada abondo se se teñen en conta os seguintes límites: i) os fogares son os que realizan o investimento en vivendas (malia que de certo non o fan ao $100 \%$, pero si nunha proporción moi maioritaria); ii) a parte das administracións públicas, incluíndo a sanidade, a educación e os servizos sociais públicos, si pódese precisar coa información dispoñible; iii) a parte asignada ao sector corporativo inclúe as empresas públicas, baixo o suposto de que os seus obxectivos e criterios de investimento son semellantes aos das empresas privadas. Ademais, inclúe tamén educación, sanidade e asistencia social de carácter privado; iv) O investimento dos fogares en equipamentos (residential equipment), que inclúe mobiliario, electrodomésticos, etc..., non se pode obter dadas as fontes de información dispoñibles e pola súa menor importancia, a efectos prácticos será considerada consumo duradeiro e non acumulación de capital.

Por último, a desagregación sectorial realízase seguindo un esquema baseado nas características de cada rama produtiva. Para iso, primeiro, considerando como o indicador máis axeitado para facer unha primeira distinción a evolución da produtividade do traballo, obtidas acudindo á base EU-KLEMS3 (O’Mahony e Timmer, 2009), o criterio de demarcación será o $2 \%$ de crecemento da produtividade do traballo, medido en horas, para o período 1981-07. Despois de facer esta primeira distinción, agrupamos as ramas pola semellanza nos procesos produtivos e a evolución do emprego.

Con iso, conséguense os seguintes grupos (véxase o Cadro 1) de sectores:

- Sectores Básicos (SB): presentan un incremento positivo da produtividade pero con destrución de emprego.

- Sectores Manufactureiros (SM): caracterízanse por un crecemento positivo da produtividade do traballo sen creación nin destrución de emprego.

- Sectores máis creadores de Emprego (SE) caracterízanse por un moi lento crecemento da produtividade do traballo pero con forte creación de emprego.

3 Os datos pódense atopar na web: http:/ / www.euklems.net. A razón de acudir a esta base de datos é a súa complementariedade coa base BBVA-IVIE (Gouma \& Timmer, 2012). 
- Sectores máis produtivos (SP) caracterízanse por un forte crecemento da produtividade do traballo e unha moderada creación de emprego.

Esta clasificación será utilizada para analizar o investimento corporativo, que conforme aos criterios metodolóxicos antes sinalados non inclúen nin o investimento dos fogares nin o realizado polas AA.PP., polo que é necesario esclarecer que o obxectivo non é explicar estes comportamentos da produtividade (o que supera amplamente os límites deste estudo), senón facilitar a identificación do patrón de acumulación sectorial ao agregar varias industrias.

Cadro 1. Clasificación sectorial do investimento Sectores básicos (SB)

1. Agricultura, gandería, silvicultura e pesca

\subsubsection{Industrias extractivas}

\begin{tabular}{ll}
\hline Sectores manufactureiros (SM) & 2.2. Manufacturas \\
\hline Sectores creadores de emprego (SE) & 3. Construción \\
4.1. Comercio e reparación \\
4.3. Hostalería \\
7. Actividades inmobiliarias "corporativas" \\
8. Actividades profesionais \\
9. "Administración privada"
\end{tabular}

10. Outros servizos

Sectores intensivos en produtividade (SP)

\subsubsection{Enerxía eléctrica, gas e auga}

4.2. Transporte e almacenamento

5. Información e comunicacións

6. Actividades financeiras e de seguros

Fonte: Elaboración conforme á descrición anterior

\section{Evidencia en perspectiva agregada}

O primeiro dos feitos observados na análise descritiva é que a FBCF total amosou unha tendencia crecente, tanto na súa relación co stock de capital neto, medido como taxa de acumulación $(\mathrm{I} / \mathrm{K})$, como na súa relación coa demanda agregada, medido en taxa de esforzo investidor (I/Y), de tal forma que a taxa de acumulación $\mathrm{I} / \mathrm{K}$ bruta amosa unha media do 7,9\%, que se incrementa moderadamente durante a primeira fase expansiva (crecemento do $0,5 \%$ ) e máis notablemente na segunda (crecemento do 2,2\%), ata acadar o máximo de I/K no ano 2006. Por iso, o investimento na economía española no só foi moi significativo, con respecto á súa evolución senón tamén superior á dos países da súa contorna (Sánchez, Sánchez \& Urtasun, 2008), dado que se materializou nun incremento do stock de capital en taxas elevadas, a 
economía española presenta unhas taxas de capitalización media, en termos de capital per cápita, con respecto ao resto de economías europeas (Mas, Pérez \& Uriel, 2015, pp. 50-54).

Polo tanto, o investimento amosa un bo comportamento tanto en termos das súas tendencias previas como en termos de comparativa internacional (Pérez, 2011), polo que non existe atraso relativo da capitalización per cápita total.

En consecuencia, outro trazo característico é o forte crecemento da Formación Neta de Capital Fixo (FNCF), calculada mediante a diferenza dos datos anuais de stock neto, e que amosa unha forte correlación co ciclo económico, crecendo substancialmente nas fases de expansión e caíndo substancialmente nas recesións, de tal forma que o investimento de reposición, destinado a cubrir a depreciación, creceu en menor medida que a FBCF, e polo tanto que a FNCF, reflectíndose na evolución da participación relativa, aínda que malia que o investimento de reposición é dominante, a súa cota de participación relativa decaeu sensiblemente a favor da de ampliación (que crece do $32 \%$ durante o primeiro período ao 45,5\% durante o segundo).

En resumo, durante todo o período produciuse un considerable aumento do I/ $K$, este aumento acelérase entre ámbalas dúas fases, e debeuse esencialmente ao incremento do investimento de ampliación durante a fase 1994-2007, con respecto á súa tendencia previa.

En segundo lugar, a composición técnica do investimento amosa un comportamento semellante. Por unha banda, o investimento en instalacións presenta tamén unha aceleración entre ámbalas dúas fases cíclicas (incrementado o seu crecemento do 3,3\% ao 5,5\%) pero aínda así o seu crecemento é menor que a FBCF dos equipamentos (aceléranse pasando do 3,5\% ao 8,4\%). Por outra banda, na participación na FBCF segue sendo predominante o investimento en instalacións (arredor de $3 / 4$ do total) pero decaendo 5 puntos na segunda fase. Como consecuencia, a proporción de equipamentos sobre instalacións creceu dende o $31 \%$ ata o $39 \%$.

Así mesmo, malia que o investimento de expansión tamén amosa unha aceleración en ámbalas dúas categorías, en participación con respecto ao total é maior nas instalacións que nos equipamentos (un $45 \%$ fronte a un 19\%), o cal se explica esencialmente pola maior depreciación destes fronte ás vivendas e outras construcións (Mas, Pérez \& Uriel, 2015, p. 165). Por iso, tamén a FNCF é sensiblemente menor nos equipamentos que nas instalacións, e amosan un crecemento mesmo máis espectacular entre ámbalas dúas fases parcialmente derivado do seu reducido volume pero tamén significativo.

En conxunto, o investimento en instalacións é o predominante, supoñendo aproximadamente $3 / 4$ partes do mesmo durante o período 1981-2007, pero é o investimento en equipamentos 0 que amosa un maior dinamismo e unha maior aceleración entre as dúas fases expansivas.

En terceiro lugar, desagregando os sectores de destino do investimento agregado, obsérvase que na FBCF: i) os SP e os SE presentan taxas de crecemento non moi dispares $(6,2$ fronte a 7,1$)$ na segunda fase de expansión, a pesar de que entre os segundos se inclúe o que amosa o maior crecemento (un 15,3\% na construción); ii) a derruba do investimento en manufacturas (do 3,9\% ao $0,8 \%$ ); iii) a escasa importancia cuantitativa dos SB en termos de participación sobre o total da FBCF e o seu moderado crecemento. iv) Como consecuencia, a participación dos SE creceu notablemente, pero non o fixo á conta dos SP (que manteñen o seu ritmo), senón esencialmente con respecto aos outros sectores (SM e SB).

O investimento de ampliación amosa os mesmos patróns, só que máis acusados, como se evidencia na proporción entre ámbolos dous, de tal forma que os SP e os SE presentan practicamente a mesma proporción durante a segunda fase expansiva (un $47 \%$ e un $46 \%$ ), namentres que as manufacturas presentan unha caída do investimento de ampliación entre as dúas fases e os SB unha clara perda de capacidade produtiva (ao presentar unha significativa caída da FNCF).

Como consecuencia, pódese afirmar que os SE son os predominantes e incrementaron a súa 
importancia ao longo da etapa expansiva, pero namentres que os SP mantiveron boas taxas de crecemento, tanto en bruta como en neta, as manufacturas e os SB sufriron unha caída importante evidenciando unha forte deterioración do investimento de ampliación.

Táboa 1: Investimento agregado

\begin{tabular}{|c|c|c|c|c|c|c|c|c|}
\hline & \multicolumn{4}{|c|}{ Crecemento } & \multicolumn{4}{|c|}{ Participación/ Medias } \\
\hline & 1981-07 & $\begin{array}{c}1981- \\
93\end{array}$ & $\begin{array}{c}1994- \\
07\end{array}$ & $\begin{array}{c}2008- \\
13\end{array}$ & $\begin{array}{c}1981- \\
07\end{array}$ & $\begin{array}{c}1981- \\
93\end{array}$ & $\begin{array}{c}1994- \\
07\end{array}$ & $2008-13$ \\
\hline $\mathrm{FBCF}$ & 4,9 & 3,3 & 6,2 & $-7,8$ & - & - & - & - \\
\hline Stock de capital & 4,1 & 3,4 & 4,7 & 1,7 & - & - & - & - \\
\hline FBCF/ K bruto & 1,4 & 0,5 & 2,2 & $-9,1$ & 7,9 & 7,2 & 8,5 & 6,6 \\
\hline FBCF Instalacións & 4,5 & 3,3 & 5,5 & $-10,5$ & 73,7 & 75,9 & 71,9 & 65,1 \\
\hline FBCF Equipamentos & 6,1 & 3,5 & 8,4 & $-2,7$ & 26,3 & 24,1 & 28,1 & 34,9 \\
\hline FBCF Equip / Inst & 1,6 & 0,3 & 2,8 & 8,6 & 35,8 & 31,8 & 39,3 & 54,2 \\
\hline FNCF & 6,4 & 3,4 & 8,9 & $-43,7$ & - & - & - & - \\
\hline FNCF Instalacións & 5,8 & 4,0 & 7,5 & $-55,9$ & 87,2 & 89,7 & 85,0 & 79,3 \\
\hline FNCF Equipamentos & 11,2 & $\begin{array}{c}14,2 \\
*\end{array}$ & $28,4^{*}$ & $-26,6$ & 12,8 & 10,3 & 15,0 & 20,7 \\
\hline FNCF Equip./ Inst. & 5,0 & $-7,1$ & 18,7 & 66,4 & 15,5 & 12,3 & 18,2 & 78,4 \\
\hline FNCF/ FBCF & 1,4 & 0,1 & 2,5 & $-39,0$ & 30,9 & 32,0 & 45,5 & 2,4 \\
\hline FNCF/ FBCF Instalacións & 1,3 & 0,7 & 1,9 & $-50,8$ & 45,2 & 41,1 & 48,7 & 24,5 \\
\hline $\begin{array}{l}\mathrm{FNCF} / \mathrm{FBCF} \\
\text { Equipamentos }\end{array}$ & 4,8 & $-7,1$ & 18,2 & $-24,5$ & 19,3 & 16,2 & 21,9 & 5,0 \\
\hline
\end{tabular}

\section{Evidencia por tipos de axentes}

Analizando agora a composición do investimento polos grupos de axentes que o realizan. Obsérvanse, primeiro, que o investimento dos fogares mantivo taxas de crecemento moi modestas na primeira fase, creceu intensamente durante a segunda fase, chegando a superar a media do período, como consecuencia do espectacular incremento da FNCF, que se en 1994 supoñía un cuarto do investimento, en 2007 supoñía a metade da FBCF (unha taxa de crecemento da cota do 5,6\%). 
Loxicamente este importante incremento do investimento de ampliación ten como consecuencia un crecemento paralelo do stock de capital. De igual forma, a participación da FBCF dos fogares amosa un patrón semellante, xa que perde importancia durante a primeira fase (do $36 \%$ ao 26\%) e gaña participación na segunda (ata o $29 \%$ en 2007).

Estes feitos parecen relacionados coa apreciación de Álvarez \& Cabrero (2010), que sosteñen que o investimento residencial tende a adiantarse no ciclo económico da produción e o investimento agregado, medido tanto en vivendas iniciadas como en visados concedidos, sendo semellante aos patróns observados noutras economías occidentais, como Estados Unidos e Alemaña.

Así mesmo, as AA.PP. (Díaz-Roldan \& Martínez, 2006; Torres, 2009), creceron a un ritmo notable durante a primeira fase, freou sensiblemente o seu crecemento na segunda fase expansiva, a FNCF creceu a taxas superiores que a depreciación durante a primeira fase, namentres que durante a segunda de feito perdeu participación en favor do investimento de reposición. A partir de 1993 comeza a reducirse progresivamente o investimento de ampliación, chegando ao $42 \%$ en 2007. A participación na FBCF total das AA.PP tivo unha maior importancia durante a primeira fase, gañando un $5 \%$ de puntos de cota, que perdería posteriormente durante a segunda fase (quedando no ano 2013 nun 7,5\%).

Con respecto ao investimento das empresas é o que amosou unha maior semellanza coa FBCF total, cunha aceleración do crecemento do 3,5\% ao 6,8\% do mesmo, e unha aceleración do investimento de ampliación aínda máis importante, do $3,1 \%$ ao $9,6 \%$.

$\mathrm{O}$ investimento corporativo amosa tamén un incremento da participación da FNCF sobre a bruta durante o período expansivo do $33 \%$ ao $39 \%$ (chegando ata o $41 \%$ ). Malia que é significativo que neste caso non supere o $50 \%$ da FBCF. Isto débese ás súas superiores taxas de crecemento da depreciación con respecto á depreciación dos fogares (loxicamente a depreciación dos bens de equipo é maior que a das instalacións e equipamentos produtivos). $\mathrm{O}$ investimento corporativo incrementou sempre a súa participación na FBCF total (do $51 \%$ no ano 1981 ao $67 \%$ no 2013 ).

Como consecuencia, o investimento corporativo tivo cada vez un maior protagonismo, sendo a variable que mellor reflicte o comportamento da FBCF total, pero os fogares e as AA.PP. contribúen notablemente (na contorna do 45\%), existindo un relevo entre ámbolos dous axentes no seu crecemento durante as dúas fases.

Táboa 2:

Crecemento

Participación / Medias

\begin{tabular}{|c|c|c|c|c|c|c|c|c|}
\hline $\begin{array}{l}\text { Investimento por } \\
\text { axentes }\end{array}$ & $\begin{array}{l}1981- \\
2007\end{array}$ & $\begin{array}{l}1981- \\
1993\end{array}$ & $\begin{array}{l}1994- \\
2007\end{array}$ & $\begin{array}{l}2008- \\
2013\end{array}$ & $\begin{array}{l}1981- \\
2007\end{array}$ & $\begin{array}{l}1981- \\
1993\end{array}$ & $\begin{array}{l}1994- \\
2007\end{array}$ & $\begin{array}{r}2008- \\
2013\end{array}$ \\
\hline $\begin{array}{l}\text { Investimento dos } \\
\text { fogares (FBCF) }\end{array}$ & 3,9 & 0,6 & 6,8 & $-10,4$ & 29,7 & 31,0 & 28,6 & 24,8 \\
\hline FNCF & 6,0 & $-1,5$ & 12,8 & $-37,6$ & 29,4 & 27,0 & 31,4 & 33,3 \\
\hline FNCF/ FBCF & 2,0 & $-2,1$ & 5,6 & $-30,3$ & 38,2 & 29,5 & 45,7 & 21,0 \\
\hline $\begin{array}{l}\text { Investimento } \\
\text { AA.PP. (FBCF) }\end{array}$ & 5,8 & 9,5 & 2,7 & $-13,9$ & 13,8 & 15,3 & 12,4 & 12,2 \\
\hline - Instalacións & 5,5 & 9,9 & 2,0 & $-13,9$ & 15,5 & 17,0 & 14,2 & 14,7 \\
\hline - Equipamentos & 6,9 & 7,5 & 6,3 & $-14,0$ & 8,8 & 10,0 & 7,8 & 7,7 \\
\hline FNCF & 6,8 & 13,5 & 1,4 & - & 17,5 & 23,4 & 12,4 & $-22,7$ \\
\hline FNCF/ FBCF & 1,0 & 3,6 & $-1,2$ & - & 45,5 & 52,8 & 39,2 & 7,3 \\
\hline
\end{tabular}




\begin{tabular}{|c|c|c|c|c|c|c|c|c|}
\hline FBCF Equip./ Inst. & 1,3 & $-2,2$ & 4,3 & $-0,1$ & 20,6 & 18,9 & 22,1 & 26,5 \\
\hline $\begin{array}{l}\text { Investimento } \\
\text { corporativo } \\
\text { (FBCF) }\end{array}$ & 5,3 & 3,5 & 6,8 & $-5,7$ & 56,5 & 53,7 & 59,0 & 63,0 \\
\hline - Instalacións & 4,7 & 3,7 & 5,6 & $-9,6$ & 57,7 & 59,6 & 56,0 & 49,0 \\
\hline - Equipamentos & 6,1 & 3,2 & 8,6 & $-2,0$ & 42,3 & 40,4 & 44,0 & 51,0 \\
\hline$-\mathrm{SB}$ & $-0,0$ & $-3,7$ & 3,2 & $-1,6$ & 3,5 & 4,8 & 2,5 & 2,6 \\
\hline$-\mathrm{SM}$ & 2,2 & 3,9 & 0,8 & $-9,8$ & 22,5 & 26,4 & 19,1 & 10,2 \\
\hline$-\mathrm{SE}$ & 8,8 & 7,6 & 9,8 & $-8,9$ & 41,4 & 34,0 & 47,7 & 45,4 \\
\hline - Construción & 10,4 & 4,9 & 15,3 & $-26,7$ & 10,8 & 7,6 & 13,6 & 10,3 \\
\hline - SP & 3,8 & 1,2 & 6,2 & 0,9 & 29,7 & 30,5 & 29,0 & 40,2 \\
\hline FNCF & 6,5 & 3,1 & 9,6 & $-29,2$ & 0,0 & 0,0 & 0,0 & 0,0 \\
\hline Instalacións & 5,5 & 4,0 & 6,8 & $-37,9$ & 79,8 & 85,4 & 75,0 & 78,7 \\
\hline - Equipamentos & 11,7 & $-1,2^{*}$ & $22,4^{*}$ & $-18,2$ & 20,2 & 14,6 & 25,0 & 21,3 \\
\hline$-\mathrm{SB}$ & $-4,7$ & - & - & - & 1,8 & 3,2 & 0,6 & $-1,6$ \\
\hline$-\mathrm{SM}$ & $-5,0$ & 7,4 & $-14,4$ & - & 15,1 & 19,8 & 11,1 & $-33,2$ \\
\hline - SE & 11,7 & 11,5 & 11,9 & $-25,7$ & 54,5 & 44,0 & 63,5 & 52,1 \\
\hline - Construción & 21,0 & 19,8 & 22,1 & - & 12,6 & 3,0 & 20,9 & $-10,1$ \\
\hline$-\mathrm{SP}$ & 2,5 & $-4,4$ & 8,7 & $-10,3$ & 26,3 & 28,7 & 24,3 & 80,9 \\
\hline FNCF/ FBCF & 1,2 & $-0,4$ & 2,5 & $-24,9$ & 36,4 & 33,0 & 39,2 & 17,4 \\
\hline - SB & $-4,7$ & - & - & - & 13,7 & 17,3 & 10,5 & 3,1 \\
\hline$-\mathrm{SM}$ & $-7,0$ & 3,4 & $-15,1$ & - & 22,9 & 26,3 & 19,9 & $-41,4$ \\
\hline$-\mathrm{SE}$ & 2,7 & 3,6 & 1,9 & $-18,5$ & 47,3 & 42,1 & 51,8 & 18,6 \\
\hline - Construción & 9,6 & 14,3 & 5,8 & - & 35,4 & 10,4 & 56,8 & $-21,9$ \\
\hline - SP & $-1,3$ & $-5,4$ & 2,3 & $-11,1$ & 31,0 & 29,1 & 32,7 & 30,4 \\
\hline FBCF/ K bruto & 1,2 & 0,1 & 2,1 & $-7,2$ & 10,5 & 9,6 & 11,3 & 8,8 \\
\hline$-\mathrm{SB}$ & $-1,2$ & $-5,2$ & 2,3 & $-1,9$ & 7,9 & 8,4 & 7,4 & 7,8 \\
\hline$-\mathrm{SM}$ & $-0,2$ & 0,9 & $-1,1$ & $-8,0$ & 9,0 & 9,2 & 8,7 & 5,4 \\
\hline$-\mathrm{SE}$ & 2,6 & 2,8 & 2,5 & $-10,4$ & 11,4 & 10,0 & 12,7 & 8,1 \\
\hline - Construción & 5,0 & 2,8 & 6,9 & $-27,2$ & 9,4 & 6,4 & 11,9 & 5,5 \\
\hline$-\mathrm{SP}$ & 0,2 & $-1,8$ & 2,0 & $-3,0$ & 11,0 & 9,9 & 12,0 & 12,4 \\
\hline
\end{tabular}

Notas: *Substituído o ano 1993 por 1994, por ter un valor negativo. ${ }^{* *}$ Pola relevancia do sector da construción amósase a súa evolución malia que forma parte dos SE.

Fonte: Cálculos a partir da base do BBVA-IVIE 
Como se observa nos dous comportamentos claramente diferenciados entre o investimento dos fogares e as AA.PP., na primeria fase as AA.PP. tiveron un papel de estímulo, namentres que na segunda toma o relevo a FBCF dos fogares. O mesmo comportamento amosa o investimento de ampliación, que foi superior na segunda fase, como consecuencia de que tanto o investimento corporativo como o dos fogares intensifican o seu crecemento.

En segundo lugar, desagregando a composición técnica da FBCF, por unha banda, a FBCF das AA.PP. concéntrase principalmente en instalacións (na contorna do 80\%) durante todo o período considerado, malia que se observa un incremento dos equipamentos a partir de 1994 . Ademáis, a ampliación produciuse con maior intensidade durante a primeira fase expansiva en ámbalas dúas variables, namentres que durante a segunda predomina a reposición.

Na FBCF corporativa, malia que dominan as instalacións e gañaron certa participación durante a primeira fase, os equipamentos melloraron a súa cota de forma progresiva e acelerada (xa que creceron a unha taxa do 8,6\%) durante a segunda fase expansiva (acadando o 46\% en 2007 superando o 58\% en 2013). A FNCF foi bastante estable nas instalacións corporativas, sendo aproximadamente do 50\% da FBCF durante todo o período e cunha escasa incidencia do ciclo económico.

Pola contra, a FNCF en equipamentos amosa un elevado grao de sensitividade cíclica en ámbalas dúas fases de crecemento (acadado o máximo no ano 2000, cun $34 \%$ ) pero sempre con reducidas taxas de participación relativa, o cal da mostra do seu forte carácter procíclico e o seu papel nas flutuacións económicas (Posada, Urtasun \& González, 2014).

Como consecuencia, o investimento en equipamentos (esencialmente das empresas) tivo unha importancia crecente, gañando participación relativa. Isto descarta a idea de que 0 investimento en instalacións tivera un efecto crowding-out sobre os equipamentos, xa que ámbolos dous tiveron un importante crecemento e de feito, os equipamentos gañaron importancia, malia que unha parte significativa fora destinado a cubrir a depreciación.

\section{Investimento sectorial corporativo}

Finalmente, para completar o patrón de capitalización é necesario desagregar sectorialmente o investimento corporativo (conforme o esquema e categorías sinaladas previamente).

Por unha banda, as manufacturas perderon progresivamente participación na FBCF (pasando de taxas da contorna do 25\% durante os anos 80 a tan só un 9\% no ano 2013) como consecuencia do seu estancamento (un 0,8\%) durante a segunda fase de expansión, o que se reflicte na caída da súa taxa de acumulación ao longo de todo el período 1981-07 (un $-0.2 \%$ ).

Os SB presentan tamén unha continuada perda de importancia, pero a súa evolución é a contraria á dos SM, durante o primeiro ciclo expansivo presentan unha notable caída que vai acompañada dunha mellora na segunda fase, a pesar diso, o I/ K presenta unha importante caída durante o período 1981-07.

Por outra banda, os SE son os que teñen un maior crecemento do investimento, e cunha relevante aceleración na segunda fase. Dentro deste grupo de ramas produtivas, é especialmente destacable o protagonismo investidor do sector da construción. As súas taxas de crecemento son, por moito, as máis elevadas en calquera das variables consideradas. Ademais, tamén presenta a aceleración entre as dúas fases cíclicas, que lle leva a incrementar o seu I/ K a case o duplo (do 6,4\% ao 11,9\%) entre ámbolos dous intervalos.

Entre tanto os SP teñen un crecemento importante no segundo período, reflectíndose 
tamén nas súas taxas de acumulación brutas, namentres que as manufacturas reducen o seu crecemento $(9,2 \%$ ao $8,7 \%$ ), os SE (do $10 \%$ ao $12,7 \%$ ) e os SP (do $9,9 \%$ ao $12 \%$ ) crecen a un ritmo notable.

Loxicamente, estes comportamentos son consecuencia do importante volume de FNCF que presentan os SE durante todo o período, e unha vez máis, con maior intensidade durante a segunda fase. Pola contra, tanto nas manufacturas como nos sectores máis produtivos o investimento predominante é o de reposición, sendo sintomática a perda de FNCF sobre a FBCF, pasando do $26 \%$ ao $20 \%$, namentres que o resto de sectores incrementan a participación da FNCF nestes mesmos anos.

En resumo, a composición sectorial do investimento empresarial amosa o feito do forte protagonismo dos SE, e dentro deles o peso da construción. Así como do importante investimento de ampliación que levaron a cabo estes sectores; e que en termos dinámicos se reflicte na acentuación do seu crecemento durante a segunda fase expansiva.

\section{Conclusións}

Neste traballo abordouse a tarefa de identificar os principais feitos estilizados do patrón de capitalización da economía española dende principios dos anos 80. Con ese obxectivo desenvolveuse unha metodoloxía inspirada principalmente nas categorías do Bureau of Economic Analysis, pero adaptadas á información dispoñible e característica do obxectivo do estudo.

Este novo enfoque permite identificar os seguintes trazos característicos do investimento na economía española:

1) En termos xerais, durante o período 1981-2007 existiu un importante aumento da taxa de capitalización.

- Existindo unha "aceleración" entre as dúas fases de auxe, é dicir., entre o ritmo de crecemento do período 1981-1993 e o período 1994-2007.

- Os dous aspectos son, esencialmente, consecuencia do intenso dinamismo do investimento de ampliación durante a fase 1994-2007.

2) Atendendo á composición técnica da capitalización do conxunto da economía:

- O investimento en instalacións é o que ten unha maior preponderancia, ao supoñer unhas $3 / 4$ partes, polo que é o elemento máis estable.

- O investimento en equipamentos é que amosa tanto un maior crecemento como unha maior aceleración, polo que é o elemento máis dinámico.

3) Con respecto á composición por axentes, obsérvase que:

- O investimento dos fogares e das AA.PP. contribúen notablemente (arredor do $45 \%$ ), existindo un relevo entre ámbolos dous axentes no seu crecemento durante as dúas fases.

- O investimento corporativo tivo cada vez un maior protagonismo, sendo a variable que mellor reflicte o comportamento da FBCF total.

- O investimento en equipamentos das empresas tivo unha importancia crecente, gañando participación relativa.

4) Por último, estudando a composición sectorial do investimento empresarial:

- O forte protagonismo dos SE, e dentro deles o peso da construción, así como do importante investimento de ampliación que levaron a cabo estes sectores; e que, en termos dinámicos, se reflicte na acentuación do seu crecemento durante a segunda fase expansiva. 
- Pódese afirmar que os SE son os predominantes e incrementaron a súa importancia ao longo da etapa expansiva, pero namentres que os SP mantiveron boas taxas de crecemento, tanto en bruta como en neta, as manufacturas e os SB sufriron unha caída importante evidenciando unha forte deterioración 0 investimento de ampliación.

Estes feitos apuntan a complementariedades no patrón de capitalización nos seus distintos niveis, a aceleración entre os intervalos vén acompañada do relevo entre o investimento dos fogares e das AA.PP., un incremento da capacidade produtiva (polo maior investimento de ampliación e o maior investimento en equipamentos) e unha localización en sectores máis baseados en creación de emprego (especialmente, o da construción).

Loxicamente cunha análise descritiva deste tipo non se poden inferir relacións causais, polo que quedan para futuras investigacións, pero pódense apuntar posibles interconexións:

- Non se observa claramente que o investimento en instalacións tivera un efecto crowding-out sobre os equipamentos, de feito, os equipamentos amosaron un gran dinamismo e gañaron importancia. O seu menor crecemento en termos netos, loxicamente, débese ás súas maiores taxas de depreciación co de equipamentos.

- É probable que haxa complementariedade entre o investimento dos fogares e das AA.PP., xa que a creación de vivendas adoita ir acompañada da dotación en infraestruturas (que supón o principal compoñente da capitalización das AA.PP.).

- É posible que existira un efecto de estímulo dende o incremento do investimento en instalacións e o forte crecemento sectorial da construción. Pola contra, a mellora nos equipamentos non foi acompañada dunha mellora substancial nas manufacturas.

En conxunto, estes feitos veñen a complementar a explicación realizada ata a data, abrindo así novas preguntas de investigación sobre o investimento en España.

\section{Referencias}

Álvarez, L. J. \& Cabrero, A. (2010). La evolución cíclica de la inversión residencial: algunos hechos estilizados. Boletín Económico. Banco de España, (10), 57-63.

Bureau of Economic Analysis (2014). Concepts and methods of the US national income and product accounts, Handbook, N. I. P.A.. U.S. Department of Commerce.

Díaz Roldán, C., \& Martínez López, D. (2006). Inversión pública y crecimiento un panorama. Hacienda Pública Española, (176), 109-140.

Gouma, R. \& Timmer, M. (2012). EU KLEMS Growth and Productivity Accounts. 2012 release. Description of methodology and country notes for Spain.

López Prol, J., \& Palazuelos, E. (2016). La relación entre beneficios e inversión en el crecimiento económico de España 1994-2007. Problemas del Desarrollo. 46(185), 111136.

Mas, M., Pérez-García, F. \& Uriel, E. (2015). Inversión y stock de capital en España (19642013): La salida de la crisis. Bilbao: Fundación BBVA.

Maza, L. Á., \& Peñalosa, J. M. (2010). La situación actual del ajuste de la inversión residencial en España. Boletín Económico, (12), 67-79.

O’Mahony, M. \& Timmer, M. P. (2009), Output, Input and Productivity Measures at the Industry Level: the EU KLEMS Database. Economic Journal, 119(538), pp. 374-403.

Pérez, F. (dir.) (2011). Patrones de Capitalización y Crecimiento (1985-2008). Fundación BBVA. Bilbao. 
Posada, D., Urtasun, A.; \& González, J. (2014). Un análisis del comportamiento reciente de la inversión en equipo y de sus determinantes. Boletín Económico. Banco de España, 41, junio

Sánchez, C., Sánchez, P., \& Urtasun, A. (2008). La inversión empresarial en España y la posición financiera de las empresas. Boletín Económico. Banco de España, (12), 31-44.

Torres, J. L. (2009). Capital público y crecimiento económico en España 1980-2004. Hacienda Pública Española, 188(1), 31-53.

Revista Galega de Economía: http://www.usc.es/econo/RGE/benvidag.htm 